\title{
NUEVAS APORTACIONES DOCUMENTALES SOBRE EL GRABADOR CRISÓSTOMO MARTÍNEZ Y SU ATLAS DE ANATOMÍA
}

\author{
Raúl Velasco Morgado
}

Universidad de Salamanca

\section{RESUMEN}

En el presente trabajo damos a conocer nuevos hallazgos documentales sobre Crisóstomo Martínez, figura clave para entender la anatomía española del Barroco y el movimiento novator. Se aportan algunos nuevos datos biográficos sobre su probable fecha y lugar de nacimiento y su desconocida familia; igualmente se dan noticias relativas a unas primeras gestiones directas del autor con la Corona en 1683 para la solicitud de la pensión que le permitiría su viaje a París. Además, se analizan los diferentes informes elaborados para la deliberación última de la Corte en esta materia y se da cuenta de los problemas que sufrió el anatomista para el cobro de las cantidades acordadas una vez desplazado a Flandes.

PALABRAS CLAVE: Anatomía. Novatores. Grabado científico. Valencia. Siglo XVII.

\section{NEW DOCUMENTARY CONTRIBUTIONS TO THE KNOWLEDGE OF CRISÓSTOMO} MARTINEZ AND HIS ANATOMICAL ATLAS

\begin{abstract}
In this paper we present new documentary findings about Crisóstomo Martínez, a key figure in understanding the Spanish Baroque Anatomy and the movement called «novator». The documents presented show some new biographical data as well as some early news regarding the author's direct negotiations with the Crown in 1683 in order to apply for the grant that would allow him to take his famous trip to Paris. We also analyze the reports prepared for the final deliberation of the Court on this matter and the problems the artist encountered in collecting the sum that had been agreed upon once he moved to Flanders.
\end{abstract}

KEY WORDS: Anatomy. Novatores. Scientific engraving. Valencia. $17^{\text {th }}$ century.

\section{CRISÓSTOMO MARTÍNEZ Y SU «ATLAS ANATÓMICO»}

El movimiento denominado novator tuvo una significación decisiva en el desarrollo de la ciencia en las últimas décadas del siglo XVII. Fue López Pi- 
ñero quien, en diversos estudios fundamentales sobre algunos de sus representantes, revisó su actividad y reivindicó su papel tradicionalmente silenciado por la historiografía tradicional ${ }^{1}$. A grandes rasgos, esta corriente sería la manifestación de la revolución científica en España a través de un grupo minoritario de estudiosos - los novatores - y de la asunción por estos individuos de los presupuestos de la nueva ciencia frente a la tradición escolástica. La caracterización como «época deslucida» del reinado de Carlos II a la luz de los intentos y logros de estos autores ha sido revisada en las últimas décadas, pues es patente que su aportación representó una alternativa en la anquilosada ciencia del Seiscientos.

En este contexto aparece en Valencia, importante foco de actividad del nuevo movimiento ${ }^{2}$, la figura de Crisóstomo Martínez $^{3}$, un personaje sin una formación inicial específicamente médica, pero con una obra radicalmente innovadora en el ámbito de la anatomía humana. Martínez no solo se habría dedicado a importar la nueva ciencia en una mera labor de asimilación de saberes foráneos, sino que habría participado activamente con producción propia en la generación singular y específica de nuevos conocimientos. Célebre por su aportación a la morfología a través de su colección de grabados anatómicos, desenvolvió su actividad profesional en el círculo de las bellas

1 El término novator lo divulgó con un sentido peyorativo el obispo de Jaén, Francisco Palanco, decidido tomista. La historiografía posterior y muy especialmente el P. Ramón Ceñal emplearon ampliamente el término que López Piñero reutilizó en un esquema de periodización que hoy es ampliamente aceptado y que, a grandes rasgos, acaba con la barrera que se colocaba en 1700 - el año del cambio dinástico — y que velaba en gran parte las relaciones de continuidad existentes entre ambos siglos. Véase LÓPEZ PIÑERO, J.M. (1979), Ciencia y técnica en la sociedad española de los siglos XVI y XVII. Barcelona, Labor.

2 Una revisión sobre el movimiento novator en el ámbito médico lo encontramos en MARtínez VidAL, A. y PARdo TOMÁs, J. (2003), Un siglo de controversias: la medicina española de los novatores a la Ilustración. En BAronA, J.L., Moscoso, J., Pimentel, J. (eds.), La Ilustración y las ciencias. Para una historia de la objetividad, Valencia, Universitat de València, pp. 107-135; y con un enfoque local que nos permite entender el marco valenciano del que parte la obra de Martínez y hacer comparación con otras áreas de la Península en PARDO TOMÁs, J. y MARTíNEZ VIDAL, A. (2007), Medicine and the Spanish novator movement: ancient vs. moderns, and beyond. En NAVARro Brotons, V. y EAmON, W. (eds.), Más allá de la Leyenda Negra. España y la Revolución Cientifica. Beyond the Black Legend: Spain and the Scientific Revolution, Valencia, Instituto de Historia de la Ciencia y Documentación López Piñero, pp. 323-344.

3 Para la biografía y obra de Martínez seguimos la obra de LÓPEZ PIÑERO, J.M. (2001), El atlas anatómico de Crisóstomo Martínez, $3^{\mathrm{a}}$ ed. Valencia, Ayuntamiento de Valencia, 2001, que contiene una profunda revisión historiográfica sobre el tema. 
artes, autodenominándose «pintor y abridor de láminas [grabador]»; sin embargo, no se conservan de él pinturas al óleo, aunque sí hasta ocho grabados en cobre para publicaciones de la época ${ }^{4}$. Guardaba así estrechas similitudes con los primeros microscopistas europeos, ajenos a las aulas universitarias y más cerca del apasionamiento del aficionado que de la sistematización de los académicos. Pero, a diferencia de muchos de sus coetáneos, la carencia de estudios médicos no le mantuvo alejado del ambiente académico, pues en Valencia mantuvo una relación fluida con profesores de medicina y, en Francia, sus cartas muestran una proximidad notable al más importante anatomista del momento, Guichard-Joseph du Verney (1648-1730), y al círculo de la Académie des Sciences.

En los años ochenta del siglo XVII, Martínez comenzó la obra gráfica por la que hoy es conocido: su serie de láminas de anatomía macroscópica y microscópica. La primera noticia de solicitud de ayuda económica a la Ciudad de Valencia para proseguir en París un trabajo al parecer ya iniciado, se venía fechando en 1685. La Ciudad, tras una misiva al rey Carlos II para que éste concediese su aprobación, accedió a proporcionar una ayuda de ochocientas libras valencianas a Martínez en cuatro pagos. Este acuerdo llegaba tras fracasar un primer intento de obtener el aval de un fiador que Martínez no consiguió procurarse. Cada fracción del pago se haría con un lapso de año y medio, comprometiéndose a enviar previamente a cada reembolso los grabados de seis de las veintidós tablas de que debía constar el «atlas». De esta manera serían completados al final de los cuatro años tanto el libro como la liquidación de la pensión.

En París, desde julio de 1687, Martínez se alojó en el Collège de Montaigue, y se dedicó a la preparación de su obra. En abril de 1689, al enfrentarse España a Francia en la Guerra de los Nueve Años, fue perseguido y acusado de espionaje, motivo por el cual, según se ha venido repitiendo por sus biógrafos, huyó a Flandes en 1690, donde moriría alrededor de 1694.

Solo una lámina de grandes dimensiones dedicada a las proporciones humanas fue editada con seguridad en vida del autor, en París, alrededor de 1689. La siguiente impresión de la misma saldría a la luz en Frankfurt-Leipzig en 1692 y, aunque López Piñero aventura el hecho de que pudo haber sido iniciativa de Martínez en aquel país ${ }^{5}$, no contamos con ninguna documentación que lo respalde. Nunca se publicó íntegra su anatomía completa. Hoy se conservan die-

4 Una relación de sus grabados en PAEZ RIOS, E. (1981), Repertorio de grabados españoles en la Biblioteca Nacional, Madrid, III, pp. 189-190.

5 LÓPEZ PIÑERO, (2001), p. 39. 
cinueve de sus láminas - dieciocho, en realidad, ya que una de ellas está repetida - en el Archivo Histórico del Ayuntamiento de Valencia.

La modernidad de Martínez no solo se limita a incorporar las nuevas técnicas del grabado europeo a la ilustración científica española, sino que, dentro de la morfología, asume el interés anatómico del Barroco por la función y deja atrás el hieratismo estático vesaliano. Asimismo, siguiendo los pasos de los microscopistas clásicos (Swammerdam, Leeuwenhoek, Hooke...), prestó una atención especial a la estructura microscópica corporal y a la embriología, con lo que su actividad trasciende la mera reproducción gráfica. De este modo, Martínez habría incorporado a la ciencia española las inquietudes e intereses más renovadores de la nueva ciencia que surgía en Europa, al margen de las universidades, y con cultivadores que en su mayoría solo se atenían a la búsqueda del conocimiento con criterios empíricos, limitación que, como hemos apuntado, nuestro grabador superaba con sus relaciones académicas.

\section{HISTORIOGRAFÍA Y LAGUNAS DOCUMENTALES SOBRE EL PERSONAJE Y SU OBRA}

Las fuentes para el estudio de Crisóstomo Martínez son de dos tipos: la documentación de archivo conservada y los textos impresos publicados en los años más cercanos a su fallecimiento. La documentación de archivo hasta ahora conocida se encuentra en los fondos documentales del consistorio municipal de Valencia. Buena parte de esta documentación fue estudiada a finales del siglo XIX por Vives Ciscar ${ }^{6}$ y está constituida, fundamentalmente, por la relación epistolar de la Ciudad con el Consejo Real para proveer la ayuda económica a Martínez para el viaje a Paris. Por desgracia, los hallazgos documentales de Vives se acotaron a la escala local, no sin que el historiador echase en falta tanto la carta enviada al Rey por el Consell el 19 de noviembre de 1686, como las deliberaciones del Consejo y de los médicos de cámara acerca del proyecto. El propio Vives Ciscar reconocía que «por más gestiones que practicamos en los Archivos de la Corte, de Simancas y en el general del reino de Valencia, no hemos tropezado con tales documentos, resultando un paréntesis en nuestro trabajo que hemos de llenar con conjeturas» ${ }^{7}$.

6 Vives Ciscar, J. (1890), Bosquejo biográfico del pintor y grabador valenciano Crisóstomo Martínez y Sorlí. Discurso leído en la sesión pública que celebró la Real Academia de Bellas Artes de San Carlos de Valencia con motivo de la apertura del curso oficial de estudios de 1890 a 1891 [...], [Real Academia de Bellas Artes de San Carlos, Valencia].

7 Vives Ciscar (1890), p. 35. 
La razón de lo infructuoso de esta búsqueda hay que atribuirlo a las vicisitudes de buena parte de la documentación relativa al Reino de Valencia. Es sabido que a la promulgación de los Decretos de Nueva Planta, seguía existiendo el Reino de Valencia dentro de la Corona de Aragón, que con sus propios fueros, dependía, en lo que a la relación con el Rey se refiere, del Consejo Supremo de la Corona de Aragón. A pesar de que los Habsburgo siguieron propiciando en un principio la integridad del archivo valenciano donde se depositaba toda la documentación relativa al Reino, la del Consejo se recogió en el Archivo General de Simancas. Al comienzos del siglo XIX los archivos del Estado sufrieron nuevos cambios; tras la Guerra de la Independencia, la documentación incautada por las tropas napoleónicas del Archivo de Simancas relativa al Consejo Supremo de la Corona de Aragón se incorporó al Archivo de la Corona de Aragón en Barcelona. Así, la búsqueda de Vives Ciscar en los archivos «de la Corte», de Simancas y del Reino de Valencia estaba abocada a ser infructuosa. Nuestro estudio se ha nutrido esencialmente de esta documentación, hasta ahora desconocida, que llegó hasta el Archivo de la Corona de Aragón a través de una peripecia que ha impedido una revisión más completa de la biografía de Crisóstomo Martínez.

Por otro lado, en el mismo fondo del Ayuntamiento se encuentra la colección de láminas que Martínez remitió a la ciudad que financiaba su trabajo y tres cartas que el grabador envió desde París al catedrático de Medicina de Valencia Juan Bautista Gil de Castelldases. Este material fue dado a conocer y estudiado por Barberá ${ }^{8}$ hace más de un siglo. Toda esta información solo sería completada décadas después por el hallazgo de la documentación relativa a la entrega de las láminas a la ciudad y fue objeto de una comunicación de García Martínez al III Congreso Nacional de Historia de la Medicina celebrado en Valencia en 1969 .

Estas fuentes manuscritas se completan con la información contenida en la escasa obra impresa del autor. En 1740 se editan en París dos de sus láminas ${ }^{10}$ con un Éloge Historique anónimo, que, como afirmó López Piñero «propor-

8 BARBERÁ, F. (1902), Valencianos ilustres. Crisóstomo Martínez. Revista Valenciana de Ciencias Médicas, 4, pp. 291-336.

9 GARCÍA MARTínEZ, S. (1971), La cátedra valenciana de anatomía durante el último tercio del siglo XVII. En VV.AA. III Congreso Nacional de Historia de la Medicina. Valencia, 10-12 de abril de 1969. Actas. Volumen II. La Medicina, la Ciencia y la Técnica en la historia valenciana, Valencia, Sociedad Española de Historia de la Medicina, pp. 167-185.

10 Durante el siglo XVIII se publicaron estas dos láminas en París en sendas ocasiones, la primera en 1740, que contiene el Éloge al que nos referimos y otra sin él, en 1780, por encargo de la Académie Royale de Peinture. 
ciona testimonios directos de algunos hechos de interés», aunque se produzcan cincuenta años después de su estancia en Francia. La profundización que este historiador, llevó a cabo sobre el movimiento novator le permitió publicar en 1964, a una obra monográfica sobre Martínez ${ }^{11}$, cuyo valor historiográfico le ha permitido llegar a una tercera edición. En este estudio, además de analizar con detalle la trayectoria y originalidad del grabador y contextualizar su personalidad en la sociedad valenciana de su tiempo, se reproducen las láminas y se transcriben las notas manuscritas y las tres cartas conservadas.

\section{REVISIÓN DE LOS DATOS BIOGRÁFICOS DEL AUTOR}

Los nuevos documentos que sacamos a la luz y transcribimos al final de este trabajo son, como ya hemos adelantado en el epígrafe anterior, la documentación administrativa conservada en el Archivo de la Corona de Aragón (A.C.A.) relativa a Crisóstomo Martínez y que comprende el período entre 1687 y 1695 . Reproducimos en el apéndice un total de ocho documentos. Aunque en el Archivo hay doce, tres son meras respuestas afirmativas que no aportan nada nuevo y que transcriben las peticiones, y otro es la carta de la ciudad de Valencia al Rey de 8 de abril de 1687, ya recogida por Vives en su estudio arriba citado. Excepto el primer documento - una solicitud del grabador de un privilegio real para que no le copiaran sus trabajos - los restantes se relacionan con las peticiones de ayuda y con las dificultades para cobrar la pensión tanto en Francia como sobre todo en Amberes una vez que salió de París.

Pocos son los datos biográficos que se tienen de Crisóstomo Martínez. Los documentos hallados en el Archivo de la Corona de Aragón ratifican unos, descartan otros y aportan alguna información novedosa. Para Vives Ciscar, Crisóstomo Martínez es el Crisóstomo Alexandrino Jusep Martínez Sorlí nacido en 1638 y del que encontró la partida de bautismo en la parroquia de San Martín Obispo y San Antonio Abad de Valencia ${ }^{12}$. Esta proposición, fue rechazada por Pérez Contel en 1955, que defendía el origen de Martínez en Játiva $^{13}$ y proponía como fecha de nacimiento el año 1640. Esta tesis sobre el origen setabense del artista había sido ya defendida por Gregorio Mayans y

\footnotetext{
11 LÓPEZ PIÑERO, (2001).

12 ViVES CiSCAR, (1890), p. 7.

13 PÉrez Contel, R. (1955), Crisóstomo Martínez Pont, Játiva.
} 
Siscar en el siglo XVIII, quien daba como fecha de nacimiento $1641^{14}$. La historiografía más reciente ha aceptado como más plausible la hipótesis de Vives. De hecho, «Sorlí» como segundo apellido oficial aparece en varios repertorios que mencionan sus obras.

Si aún cabía algún género de dudas, a la vista de la nueva documentación, parece un hecho constatable su nacimiento en la ciudad de Valencia. Solo basta con leer las expresiones: «natural de la ciudad de Valencia» ${ }^{15}$, «tan interesante gloria para la siudad un yjo como el autor» ${ }^{16} \mathrm{o}$ «la Ciudad a quien su hijo dedica la obra» ${ }^{17}$, que aparecen continuamente en los documentos y que, dada su rotundidad no cabe atribuir a un interés puntual por conseguir la ayuda solicitada. Más dudas ofrece, en cambio, la información sobre la fecha de su nacimiento. En 1687 el pintor, en su solicitud al rey, afirmaba tener más de cincuenta años de edad ${ }^{18}$. De aceptar este testimonio - que podría interpretarse de otro modo como un mero intento de inducir compasión en el monarca y no como un dato objetivo-, colocaríamos su fecha de nacimiento antes de 1637. Esta fecha, que apenas dista un año de la propuesta por Vives Ciscar, se aleja notablemente de las hipótesis de Mayans y Siscar y de Pérez Contel.

Sobre su familia, de la que hasta ahora carecíamos de información, recogemos noticia de su existencia. Su esposa y sus cuatro hijos vivían en Valencia mientras él se encontraba en París y fueron presentados por el artista como su principal preocupación a la hora de solicitar una ayuda económica. Debió contraer matrimonio tardíamente, pues el mayor de hijos solo tenía seis años en $16871^{19}$.

14 Mayans y Siscar, G. (1854), Arte de pintar. [...] Obra póstuma. Publícala un individuo de su familia, Valencia, Imprenta de José Rius, p. 173.

15 Petición de Crisóstomo Martínez a Carlos II para que le conceda privilegio para de que no se copien sus láminas. Madrid, 28 de Julio de 1683. Archivo de la Corona de Aragón (A.C.A.) Consejo de Aragón. Leg. 0816. n ${ }^{\circ}$ 33/1. (Documento 1 del anexo documental).

16 Solicitud de Crisóstomo Martínez al Rey para que medie con la ciudad de Valencia. 11 de abril de 1687. A.C.A. Consejo de Aragón. Leg. 0828. nº 88/1. (Documento 5 del anexo documental).

17 Cosme Caudel, 24 de noviembre de 1691. Oficio de Cosme Caudel, procurador de Crisóstomo Martínez, a Carlos II para que se haga el segundo pago de la pensión del grabador. A.C.A. Consejo de Aragón. Leg. 0929. n 247. (Documento 6 del anexo documental)

18 Solicitud de Crisóstomo Martínez al Rey para que medie con la ciudad de Valencia. 11 de abril de 1687. A.C.A. Consejo de Aragón. Leg. 0828. no 88/1. (Documento 5 del anexo documental).

19 Solicitud de Crisóstomo Martínez al Rey para que medie con la ciudad de Valencia. 11 de abril de 1687. A.C.A. Consejo de Aragón. Leg. 0828. nº 88/1. (Documento 5 del anexo documental). 
El último dato biográfico lo encontramos cuando afirma en 1684 que «ha treinta y dos años que vine aplicado a la pintura $\rangle^{20}$, por lo que podemos situar a Crisóstomo Martínez comenzando su carrera de pintor hacia el año 1652, con poco más de quince años de edad. Esto contradice la suposición de Vives Ciscar de que, en unos primeros años, seguiría el oficio paterno, que, en el caso de «su» Crisóstomo Martínez Sorlí, era «belluter» (tejedor de terciopelo), para después dedicarse al arte. Una afirmación que ya parecía desmentir Barberá, que no pudo localizar a nuestro autor en los archivos de esta profesión a pesar de encontrar en este gremio a parte de la familia de aquel Martínez Sorlí21

\section{UNA OSADA PETICIÓN A LA CORTE}

El bibliógrafo ilustrado José Rodríguez había propuesto en su Biblioteca valentina el año 1680 como fecha de comienzo de las láminas anatómicas ${ }^{22}$. A la vista de la nueva documentación podemos asegurar que los trabajos comenzaron alrededor de 1683, ya que en 1687 afirma llevar «más de cuatro años» trabajando de manera exclusiva en las láminas sin ganar «un real en su facultad $»^{23}$. De ese año es una información muy interesante sobre el contacto de Crisóstomo con la ciencia europea. López Piñero aseguraba que su primera obra anatómica surgió exclusivamente de las relaciones con el mundo universitario valenciano de la época y afirmaba que las primeras láminas se realizaron antes del viaje a París. Sin embargo, en la documentación descubierta, el propio Martínez asegura en 1683, que su técnica la ha conseguido con «industrial y estudio en otros países», dato que advierte de una relación temprana con la Europa científica de su tiempo aun antes de emprender su conocido viaje.

Hemos localizado asimismo una solicitud de ayuda al monarca del propio Martínez fechada en 1684, un año anterior a la documentación conocida sobre su actividad. El escrito advierte de una iniciativa propia del grabador ante Carlos II, actuando así al margen del ámbito municipal y de la administración

20 Petición de Crisóstomo Martínez a Carlos II. s.f. [Recibido en Madrid en agosto de 1684]. A.C.A. Consejo de Aragón. Leg. 0826. nº 40/4. s/d. (Documento 2 del anexo documental).

21 BARBERÁ, (1902), p. 330.

22 RodrígueZ, J. (1747), Biblioteca valentina [...], Valencia, pp. 103-104. Citado por LÓPEZ PIÑERO, (2001), p. 30.

23 Cosme Caudel, 24 de noviembre de 1691. Oficio de Cosme Caudel, procurador de Crisóstomo Martínez, a Carlos II para que se haga el segundo pago de la pensión del grabador. A.C.A. Consejo de Aragón. Leg. 0929. n² 247. (Documento 6 del anexo documental) 
del Reino de Valencia ${ }^{24}$. En dicha solicitud define sus objetivos iniciales: «[el estudio y dibujo de] las partes, miembros, huesos, arterias, músculos y nervios que gobiernan el movimiento del cuerpo humano de que hacen las verdaderas acciones que postura».

A pesar de que se emplean en el texto términos de claro origen vesaliano, como el mismo de «fábrica», e incluso cita al maestro flamenco y a Valverde de Hamusco, Martínez manifiesta con estas palabras un interés por el dinamismo y por la función más allá del estatismo del cuerpo entendido como edificio que había defendido la morfología del XVI. Este acercamiento a una anatomía funcional, un rasgo característico de la anatomía del Seiscientos, ya había sido advertido por López Piñero como una de las características novedosas de la aportación de nuestro autor ${ }^{25}$. Resulta llamativo que en nada alude en esta primera súplica a la microscopía ni a la embriología que, como hemos comentado anteriormente, serían sus otros aspectos innovadores. Tal ausencia podría hacernos pensar que estos dos rasgos de su obra aparecerían con posterioridad a esta carta.

Aun careciendo de formación académica, la relación de Martínez con algunos miembros del claustro universitario de Valencia fue estrecha. Ya lo apreció en su día Vives Ciscar ${ }^{26}$, cuando identificó a Gil de Castelldases, catedrático de Prima de la Universidad de Valencia, como custodio de los envíos de Martínez. Volviendo a la nueva documentación, en ésta su primera solicitud no solo afirma que su obra había sido revisada y aprobada antes de enviársela al Rey por los médicos de aquella universidad, sino que se coloca a sí mismo a la altura de los grandes profesores del Estudio General citando como precedente de su pensión la concedida al doctor Collado, catedrático en aquel estudio, que fue becado para desplazarse a Montpellier con el fin de ampliar sus conocimientos sobre simples ${ }^{27}$.

Con el fin de tomar una decisión, el monarca solicitó información al virrey de Valencia, Pedro José de Silva, Conde de Cifuentes, quien a su vez pidió

24 Petición de Crisóstomo Martínez a Carlos II. s.f. [Recibido en Madrid en agosto de 1684]. A.C.A. Consejo de Aragón. Leg. 0826. nº 40/4. s/d. (Documento 2 del anexo documental).

25 LÓPEZ PIÑERO, (2001), p. 45.

26 ViVES CisCAR, (1890), Anexo documental 2, sin p.

27 Aporta el dato de que el doctor Collado estuvo «detenido» en aquella ciudad durante cuatro años. Creemos que se está refiriendo al valenciano Lluís Collado (1520-1589), discípulo de Vesalio que vivió un siglo antes que Crisóstomo, y, en un primer tiempo fue catedrático de simples de la Universidad valenciana. Sobre el vesalianismo en Valencia véase LóPEZ PIÑERO, J.M. (1979), The vesalian movement in sixteenth Century Spain. Journal of the History of Biology, 12, 45-81. 
dictamen tanto a los médicos de Cámara como a la Ciudad de Valencia. Remitió las deliberaciones al Consejo de Aragón junto con todos estos documentos junto con una «caja de oja de lata» que contenía treinta y cuatro dibujos preliminares, que complementaban «quattro que ya están en esa cortte en tabla grande» que había mandado el autor junto con su petición ${ }^{28}$.

La Ciudad emitió informe favorable previa consulta al Claustro de Doctores, organismo que agrupaba a los médicos con título de doctor que vivían y ejercían su actividad en la ciudad de Valencia y sus alrededores ${ }^{29}$. Aunque sus funciones eran fundamentalmente de tipo gremial, ejerciendo el control local del ejercicio de la medicina, aquí constatamos unas atribuciones como órgano consultivo.

Las firmas del documento emitido por dicho claustro, que lleva fecha del 23 de julio de $1686^{30}$, no corresponden a la totalidad de sus miembros — que serían unos cincuenta - sino a la llamada «Junta de electos». Contamos con el dato de que para dicha junta se habían elegido nueve doctores tres años antes ${ }^{31}$, pero solo aparecen cinco en este documento. Tres son catedráticos: el ya mencionado Gil de Castelldases, su antecesor jubilado Felip Juliá Rodríguez de Gilbau, y Matías García. La presencia de este último entre los suscriptores es digno de destacar puesto que este catedrático de anatomía era un defensor acérrimo del galenismo. No obstante, paradójicamente, era también un férreo defensor de la observación científica experimental e incluso la utilizó para rebatir las ideas de la nueva ciencia ${ }^{32}$. Los otros dos que firman el informe son Juan José Viñau, el «médico más anciano» del Hospital y Agus-

28 A.C.A. Consejo de Aragón. Leg. 926. n 14/1. 19 de noviembre de 1686. Informe del Virrey de Valencia sobre la petición de Crisóstomo Martínez. Sin fecha; A.C.A. Consejo de Aragón. Leg. 826. $\mathrm{n}^{\mathrm{o}}$ 40/1. (Documento 3 del anexo documental). Informe del Consejo de Aragón sobre el asunto Crisóstomo Martínez. 29 de noviembre de 1686 y A.C.A. Consejo de Aragón. Leg. 0613. $\mathrm{n}^{\circ}$ 12. (Documento 4 del anexo documental).

29 Sobre la estructura de este claustro véase MARZAL RodRíGUEZ, P. (2003), Doctores y catedráticos. Los claustros del Estudio General de Valencia (1675-1741), Valencia, Universitat de València, sobre todo sus pp. 62-105, donde aborda el claustro médico.

30 Informe de comisión médica valenciana sobre asunto Crisóstomo Martínez. Valencia, 23 de julio de 1686. A.C.A. Consejo de Aragón. Leg. 826. $n^{\circ}$ 40/3. (Documento 3 del anexo documental).

31 MARZAL RodríGUEZ, P. (2003), p. 115.

$32 \mathrm{Y}$ es que, este galenista «había asimilado inadvertidamente la mentalidad metodológica de sus adversarios» tal y como asegura LÓPEZ PIÑERO, J.M. (2000), La facultat de Medicina. En VVAA, Cinc segles i un dia. Valencia: Universitat de Valencia, p. 53. Este apoyo ya había sido intuido, aunque sin bases documentales, por GARCíA MARTínEZ (1971), p. 175. 
tín Abaas. Se echa de menos aquí la presencia del catedrático de «herbes» Gaudenci Senach y de los otros tres miembros de la junta que no aparecen entre las firmas; sin embargo, no se puede elucubrar sobre las razones de tales ausencias por no haberse hallado hasta el momento la documentación relativa a su reunión.

En el informe, la Junta destaca fundamentalmente, no el contenido, publicado en numerosos tratados de anatomía modernos, - ellos citan de nuevo a Vesalio y a Valverde - sino «la nueva y fácil método con que expresa dichas partes $\rangle^{33}$. Este informe se convierte en una prueba más de la existencia en los círculos médicos de la ciudad de Valencia, incluso entre los personajes más conservadores de la comunidad científica, de un evidente apoyo a la innovación.

En su informe último, el virrey llama la atención sobre una interesante novedad que no se encuentra referida en ninguna de las exposiciones que le fueron remitidas y que, siendo el Conde de Cifuentes un profano en las ciencias médicas, debió recoger de algún comentario ocasional de alguno de los informantes. En efecto, el virrey advertía que en la persona de Martínez se unían el artista y el hombre de ciencia a diferencia de otras obras semejantes producto de una doble colaboración que no era deseable. Decía: «aunque ay autores que an escripto sobre esta materia, como en ella solo concurrió lo científico de la facultad y ubieron de valerse de harttífizes, salieron las obras con muchos yerros en los dibujos $\rangle^{34}$. Esto significaba toda una reivindicación de una experiencia nueva frente a los hábitos tradicionales.

El resultado de todas las exposiciones de los expertos derivó en la ayuda otorgada por el Consell municipal, que, según su informe final, empleó dinero procedente de «la bolsa del Morbo», que era la que dedicada a las epidemias $\mathrm{y}$ atenciones generales de higiene pública. Desde la Corte, se instaba también a la Diputación a que colaborase en la beca, puesto que los primeros cálculos preveían unas necesidades en torno a cuatro mil libras valencianas. Esta cantidad, que no era cubierta ni en una cuarta parte por lo concedido por la Ciudad, da una idea de la magnitud del primer proyecto de Martínez. A pesar de la recomendación no se encuentra en la documentación conservada referencia

33 Un estudio sobre la novedad iconográfica de Martínez al interpretar dichas partes y sus relaciones lo encontramos en: VALVERDE, N. (2009), Small Parts: Crisóstomo Martínez (16381694), Bone Histology and the Visual Making of Body Wholeness, Isis, 100(3): pp. 505-536.

34 Informe del virrey de Valencia sobre el asunto de Crisóstomo Martínez. Sin fecha. Crisóstomo Martínez. A.C.A. Consejo de Aragón. Leg. 826. nº 40/1. (Documento 3 del anexo documental). 
alguna a una intervención de esta institución en la financiación del grabador, por lo que cabe deducir que ni siquiera se plantearon la posibilidad de colaborar en el proyecto.

\section{LOS PROBLEMAS CON EL PAGO Y LA ENTREGA DE LA OBRA}

Entre el primer pago de doscientas libras, hecho efectivo en mayo de 1687, y la entrega en 1695 de las dieciocho láminas conservadas a la ciudad de Valencia, existía un vacío documental que se palía en cierta medida por la nueva documentación aquí presentada. Vives Ciscar indagó en los libros de cuentas de la ciudad y no encontró los restantes pagos a Martínez, deduciendo que no se hicieron ${ }^{35}$. A la luz de la nueva documentación encontrada se confirma de manera fehaciente esta hipótesis. En 1691, cuando ya había pasado el primer plazo para la entrega de láminas y había llegado el momento del segundo anticipo, la Ciudad de Valencia se negó al pago alegando incumplimiento del compromiso por parte del artista: no había enviado las trescientas impresiones pactadas. Se encontraba ahora Crisóstomo en Amberes «por averlo desterrado de los reynos de Francia cierta ymbidia» entre los personajes más conservadores de la comunidad científica, y había contratado y otorgado poderes como procurador a un tal Cosme Caudel, presbítero, para que cobrase la cantidad pendiente en su nombre ${ }^{36}$.

El hecho es que Martínez se había dedicado íntegramente a la investigación y a realizar nuevos dibujos y no a la impresión, incumpliendo por esta razón la entrega acordada y dando pretexto a la Ciudad para desentenderse del pago. El trabajo del artista había superado las 24 láminas inicialmente comprometidas hasta convertirse en 44 , cuarenta y una de las cuales fueron enviadas a la Corte como prueba de su esfuerzo y dedicación ${ }^{37}$. Lamentablemente, estas láminas, que casi doblaban en número a las conocidas, se han perdido y no podemos conjeturar hasta donde había llegado la actividad, como artista y estudioso, del valenciano.

35 Vives CisCAR (1890), p. 36.

36 Cosme Caudel, 24 de noviembre de 1691. Oficio de Cosme Caudel, procurador de Crisóstomo Martínez, a Carlos II para que se haga el segundo pago de la pensión del grabador. A.C.A. Consejo de Aragón. Leg. 0929. n 247. (Documento 6 del anexo documental)

37 Cosme Caudel, 24 de noviembre de 1691. Oficio de Cosme Caudel, procurador de Crisóstomo Martínez, a Carlos II para que se haga el segundo pago de la pensión del grabador. A.C.A. Consejo de Aragón. Leg. 0929. n² 247. (Documento 6 del anexo documental) 
En una de las cartas relativas a estos grabados perdidos encontramos la anotación: «Las láminas se las llevo el P. Borja» ${ }^{38}$. La documentación no nos da más datos sobre este personaje, pero bien pudo ser Francisco Antonio de Borja y Centellas y Ponce de León (1659-1720). Este clérigo, que alcanzaría años después el rango de cardenal, aún no había sido nombrado obispo en estas fechas y era por entonces canónigo de la Catedral de Toledo donde ostentaba el arcedianato de Calatrava. En la corte, era sumiller de cortina del Rey y se le había nombrado miembro del Consejo de Estado y del Consejo de Aragón ${ }^{39}$, donde llegó a ser regente por Valencia ${ }^{40}$. Todos estos datos que avalan su relación con la corte y con el Consejo encargado del asunto de Martínez le convierten en un firme candidato a ser él quien se llevó las láminas desaparecidas.

Carlos II, a la vista del trabajo remitido, envió una nueva orden a la ciudad de Valencia en 8 de diciembre de 1692 para que se le pagara parte de lo acordado (cuatrocientas libras). A pesar de ello, la Ciudad se reafirmó en el incumplimiento de lo convenido y decidió no pagarle ${ }^{41}$. Martínez no se arredró ante este desinterés y, consciente de la importancia y dimensiones de la labor desarrollada, dirigió su petición expresamente al monarca pidiendo su intervención ante la ciudad para conseguir la ayuda económica. Perteneciente a un gremio artesanal, reivindicaba además un mayor reconocimiento público de su labor en forma de títulos y alguna forma de honor. Caudel solicitaba en su nombre: «como Vuestra Magestad y sus gloriosos antesesores lo an costumbrado y a esta invitasión lo estilan las demas nasiones, [se le pague] no solo con $\mathrm{e}[x]$ presivos premios de maravedises sino con los lustrosos de nobleza y onores» ${ }^{42}$. Una petición que no carecía de precedentes en la historia de la anatomía (Vesalio acogido en la corte de los Austrias españoles un siglo an-

38 Cosme Caudel, 24 de noviembre de 1691. Oficio de Cosme Caudel, procurador de Crisóstomo Martínez, a Carlos II para que se haga el segundo pago de la pensión del grabador. A.C.A. Consejo de Aragón. Leg. 0929. n 247. (Documento 6 del anexo documental)

39 Sobre la linajuda familia del futuro cardenal, véase RuANO, F. (1779), Casa de Cabrera en Córdoba [...], Córdoba, en la oficina de Don Juan Rodríguez, p. 83

40 Acerca de las atribuciones de este cargo véase ARrietA AlBERDI, J. (1994), El Consejo Supremo de la Corona de Aragón (1494-1707), Zaragoza, Institución Fernando el Católico, pp. 360-362. Sobre Borja, Ibid. p. 608.

41 El licenciado Cosme Caudel reclama la cantidad pactada por el libro de Anatomía, sin fecha [1693]. A.C.A. Consejo de Aragón. Leg. 0932. nº 87/1. (Documento 7 del anexo documental).

42 Solicitud de Crisóstomo Martínez al Rey para que medie con la ciudad de Valencia. 11 de abril de 1687. A.C.A. Consejo de Aragón. Leg. 0828. nº 88/1. (Documento 5 del anexo documental). 
tes, o su contemporáneo Thomas Bartholin en la de Cristián V de Dinamarca), y que Martínez parecía conocer; como si desease encontrar en la corte del Hechizado un mecenas a la altura de su arte y en sintonía con otros antecedentes regios destacados.

A pesar de que sus peticiones caían en saco roto, el pintor siguió con sus investigaciones morfológicas. En 1693 informaba de que había seguido trabajando en una nueva tabla «que consta de vara y tres quartas de alto $[1,40 \mathrm{~m}] \mathrm{y}$ contiene un retrato cierto y fidedigno de la nervología(sic) de el hombre de el tamaño del natural» ${ }^{43}$. La palabra es legible solo parcialmente, incluso es interpretada como «herbología de el hombre» en la respuesta del Consejo de Aragón a la Ciudad ${ }^{44}$. Para nosotros, la trascripción más correcta sería la de «nervología», en correspondencia con una posible dedicación en Flandes al estudio de la neuroanatomía. De esta forma dedicado probablemente al estudio del sistema nervioso periférico, habría completado el estudio de las partes que «gobiernan el movimiento» tal y como anunciaba en su primer escrito. Esta sería la última referencia documental directa que nos ha llegado de nuestro autor.

Por último, haremos notar que, en noviembre de 1695, el Consejo volvía a preocuparse por el trabajo de Martínez y solicitaba información al virrey sobre el proyecto anatómico. Las únicas noticias que éste pudo darles es que, tras el envío de las diecinueve láminas que conocemos y su traslado a los territorios de la Corona en Flandes, nada se sabía de él. La respuesta del Virrey añadía otra versión sobre el motivo de su marcha de París al afirmar que «començando la Guerra, le desterró el Rey de Francia» ${ }^{45}$.

Aquí se pierde el rastro sobre la vida y la obra de Crisóstomo Martínez, quien desaparece en Amberes al igual que la mayoría de su obra gráfica.

\section{CONCLUSIONES}

Los documentos conservados en el Archivo de la Corona de Aragón nos muestran a un Crisóstomo Martínez que comienza sus investigaciones anatómi-

43 El licenciado Cosme Caudal reclama la cantidad pactada por el libro de Anatomía, sin fecha [1693]. A.C.A. Consejo de Aragón. Leg. 0932. nº 87/1. (Documento 7 del anexo documental).

44 El Consejo de Aragón a la Ciudad de Valencia sobre el asunto Martínez. A.C.A. Consejo de Aragón. Leg. 0932. no 87/2. 1693.

45 Respuesta de Carlos Homo dei Moura y Pacheco, virrey de Valencia sobre el estado de la obra de Martínez, noviembre de 1695. A.C.A. Consejo de Aragón. Leg. 0848. 52/3. (Documento 8 del anexo documental). 
cas en contacto con la transición que se vivía en la Europa de su siglo desde la argumentación silogística a la experimentación que se vivía en la Europa de su siglo, mediante una experiencia vital personal de viajes al extranjero, incluso antes de la conocida pensión a París. Fruto de este contacto y de un trabajo no remunerado, el grabador completa un total de cuarenta y cuatro láminas de las que solo se conservan dieciocho.

Respecto a la cuestión de la pensión otorgada por la Ciudad de Valencia, hemos rescatado los informes de los diferentes comités, que acreditan el temprano apoyo del claustro de doctores de Valencia (galenistas incluidos) al trabajo de Martínez. Sin embargo, su empeño en el trabajo de investigación y dibujo y la imposibilidad material para completar el trabajo manual de impresión en los plazos exigidos por el Consistorio, derivaron en un enfrentamiento legal del que no obtuvo beneficios económicos. A pesar de todo ello, el artista prosiguió sus investigaciones anatómicas, añadiendo a sus intereses la neuroanatomía. Con todo ello, el pintor valenciano se convirtió en una figura clave para entender la Anatomía española de su siglo a pesar de haberse perdido al menos dos tercios de su obra anatómica.

\section{ANEXO DOCUMENTAL}

Documento 1

Madrid, 28 de julio de 1683. Petición de Crisóstomo Martínez a Carlos II para que le conceda privilegio para de que no se copien sus láminas.

A.C.A. Consejo de Aragón. Leg. 0816. nº 33/1.

Crisóstomo Martínez, natural de la ciudad de Valencia, pintor y abridor de láminas dize: que aviendo conseguido con su industrial y estudio en otros países alguna habilidad y primor en inventar y abrir en láminas, se sigue que otros abridores de láminas de no tanta habilidad imitan y abren en láminas las obras ya abiertas por el suplicante de lo que se siguen dos daños: el uno el quedar el suplicante defraudado de sus propios trabajos y tal vez desacreditado y el otro el que como sea más fácil el imitar y copiar [que] el inventar, no se aplican al estudio propio y pudiendo ser buenos artífices se quedan en una medianía y el suplicante sin el fruto de su mayor aplicación. Por la que suplica a V. M. sea servido concederle Real Privilegio para que ninguna persona en dicha ciudad y reyno pueda copiar abriendo en láminas sus obras abiertas en láminas pues de esta suerte será el suplicante dueño de las suyas propias y los demás se alentarán a idear e inventar por diferente camino y se perficionarán en este arte, de lo que recibirá particular merced, de la real mano de Su Magestad.

[nota al dorso]: Madrid Julio 28 de 1683; [...] Ynforme el Virrey 


\section{Documento 2}

Sin localización, agosto de 1684.

Petición de Crisóstomo Martínez a Carlos II.

A.C.A. Consejo de Aragón. Leg. 826. n 40/4.

Crisóstomo Martínez, vecino y natural de la ciudad de Valencia dice: que por [ilegible] inclinación ha treinta $\mathrm{y}$ dos años que viene aplicado a la pintura que juntamente a abrir láminas. Que uno y otro se gobierna por una misma idea y para lograrlo todo con la valentía y perfección del dibuxo se ha empleado en la inteligencia de las partes, miembros, huesos, arterias, músculos y nervios que gobiernan el movimiento del cuerpo humano de que hacen las verdaderas acciones que postura, efectuando por este medio la perfección del dibuxo. Y aunque sobre la materia han escrito diferentes sujetos como son Besalio, Vallverde y otros, ha procurado adelantar el juicio de calidad, que le parece haría agravio a su patria y reino en no manifestar a todos una obra tan soberana, como lo es la armazón y fábrica del cuerpo humano con las circunstancias que lo goviernan y con la indicación de los movimientos con tan (legible) expresión que visiblemente se conoce reducido a veinte y dos tablas o láminas de marca mayor, explicando todo con cifras, que van al margen de la pintura sin tener más efectos que la expresión de la clave, que manifiesta la inteligencia de las cifras; obra tan útil que a un tiempo ha de ser favorable a los pintores, a los dibujantes y con mayor logro para los médicos, teniendo como tienen estas tablas reducida toda la anotomía ( $\underline{\mathrm{sic}}$ ) que, lo que los autores han explicado con dilatados volúmenes, lo enseña y manifiesta visiblemente, con que con corto estudio lograra mucho de calidad; que lo han admirado los médicos de la Universidad de Valencia aprobándola por singular, que como tal, han solicitado ponerla en execución. Y por ser esta materia de muchísimo trabajo y coste, que ecede la posibilidad del suplicante que para dicho effeto se ha de conducir a reinos estraños, donde las prensas, las aguas y las tintas hazen luzir con perfección las estampas que para cada lámina son menester de (ilegible) cabales e empleo; con que en las jornadas que gastará de ida y buelta y detención para labrar las láminas, y tirar las estampas llegará a quatro años y al mismo tiempo se le ofrecerá el gasto de su persona que el de su familia, que dexará en Valencia, y el de la fabrica que todo lo hace muy considerable que no la ha de poder suportar si no se socorren la ciudad de Valencia y el Reino con algunas aiudas de costa para alimentos de su familia, puesto que ha de redundar y ceder en beneficio y autor dado dellos y en utilidad de aquella universidad para el fácil estudio de la anotomia ( $\underline{\mathrm{sic}})$, haziendose por este medio más celebre que es el fin a que ha mirado siempre la ciudad, pues para el aumento de aquella universidad y mayor lustre de aquel reino imbió a sus expensas al Dotor Collado a la Universidad de Mompeller ( $\underline{\mathrm{sic}})$, para que allí aprendiesse los saludables remedios de aquella escuela y ilustrase después la Universidad de Valencia, a donde volvió haviendo estado detenido el Mompeller ( $\underline{\text { sic) }}$ quatro años.

Todo ello Señor representa a V.M. para que se logre un beneficio tan conocido [...] 


\section{Documento 3}

Informes varios sobre la petición de Crisóstomo Martínez..

A.C.A. Consejo de Aragón. Leg. 826. nº 40.

Documento 3a

Sin localización, [1685].

Informe del virrey de Valencia.

\section{Señor}

Con el despacho de 18 de agosto pasado me manda V.M. informe sobre la pretensión que tiene Crisóstomo Martínez para que la Ziudad y Reyno le dé una ayuda de costa para que pueda sacar a luz la obra que tiene travaxada donde en la misma se dibuja y declara la intelixencia de las partes, miembros, guesos, arterias, músculos y nervios deel cuerpo umano y que gobiernan su movimiento. Por ser tan grande el costo que a de thener en esta obra y ser cortos sus medios y que juntamente se sirva V. M. dispensar en las hórdenes y estatutos que ubiere en contrario que, junto con lo que yo entendiere, envié algunos dibujos deestas láminas comunicando la materia con personas yntelixentes $\mathrm{y}$, habiendo echo juntar los medios de primera graduación, ysieron caval exsamen dela obra y convinieron era utilísima para médicos y cirujanos y para el estudio de la nothomia ( $\underline{\mathrm{sic}})$ porque, aunque ay autores que an escripto sobre esta materia, como en ella solo concurrió lo científico de la facultad y ubieron de valerse de harttifizes, salieron las obras con muchos yerros en los dibujos. Demás que no ay alguna impresa tan llena como esta y aunque este informe fue tan a favor de la obra como quien ama de contribuir a la ayuda de costa, (legible) la Ziudad y Reyno quise oírles sobre esta pretensión, y la ziudad responde con el ynforme que remito adjunto a que acompaña el que an echo los médicos. Y la Diputación respondió que no thenía que añadir, que aguardaría la resolución de V.M. para juzgar la causa y deliberar la ayuda de costa y considerando la utilidad de la obra y que me aseguran que el costte a de pasar de quatro mill libras, de no acompañar la representación de la ziudad y convenir en la ayuda de costa que tiene deliberada con las condiciones que en su ynforme expresa y tanvién será justo ayuden algo la Diputación si bien cantidad limitada respetto de sus muchos emperos para que los hijos deste reyno se animen al trabajo y se logre el provecho inteligente que deesta obra se a de seguir y juntamente remito 34 dibujos sin conttar quattro que ya estan en esa cortte en tabla grande según el horden que a de guardar.

Documento $3 b$.

Valencia, sin fecha.

Informe de la Ciudad de Valencia.

Excelentísimo Señor,

En vista de la Real Carta de S.M. de 18 de Agosto de 1685 y memorial adjunto en que se sirve de pedir informe a V.E. sobre la pretensión de Crisóstomo Martínez; la Ciudad 
debe decir a V.E. que, aviendo hecho examinar la obra que pretende sacar a luz en veintydos tablas de marca mayor sobre la notomia ( $\underline{\text { sic) }}$ del cuerpo humano y su explicación dicho Martínez a los catedráticos y médicos de mayor intelligencia de esta ciudad, han respondido uniforme (como consta por su relación) que dicha obra, a de ser de grande beneficio y utilidad a la salud pública, y por consiguiente, digno el autor de que se le aliente ayudándole en quanto fuese pusible para que la obra llegue a su devida perfección y a salir a la luz pública. Y así parece a la Ciudad que se le podran dar al dicho Crisóstomo Martínez de la bolsa del Morbo (que es a la que toca cuidar de la salud pública) ochocientas libras en quatro años, ducientas en cada uno, con obligación de que aya de dedicar esta obra a la ciudad, para que conste lo que dezea y trabaja por el aumento y lustre de las siencias y salud pública y lo que alienta en quanto puede a los que se aplican al estudio de cosas y trabajos grandes, como lo es este. Y también con obligación de dar fiadores a satisfacción de la Ciudad, que dentro de dichos quatro años dará concluida y impresa con toda perfección a la dicha obra y que, en caso de no hazerlo, aya de restituir las cantidades que hubiere cobrado; y espera la ciudad sera servido V.E. informarlo en esta conformidad.

Documento $3 \mathrm{c}$

Valencia, 23 de julio de 1686.

Anexo que corresponde al dictamen del claustro de doctores médicos de Valencia..

De orden y comisión de los muy ilustres señores jurados de esta Ilustre Ciudad de Valencia hemos visto una obra hecha por Crisóstomo Martínez, pintor, vecino y natural de esta ciudad de Valencia, la qual en veinte y dos tablas o láminas de marca mayor, tiene estampadas y distribuidas toda la historia anatómica, expresando clara y distintamente todas las partes, miembros, huesos, arterias, musculos, venas y nervios que rigen el movimiento y sustento del cuerpo humano; y, aviéndola visto en diferentes occasiones con toda atención y cuidado, no obstante que ay mucho ya estampado de esta materia por el doctor Besalio ( $\underline{\mathrm{sic}})$, Valverde, y otros gravissimos autores, somos de sentir ser obra muy útil y necesaria para la fácil inteligencia de todas las partes del cuerpo humano, por la nueva y fácil método con que expresa dichas partes, redundando en gravísima utilidad, así de los médicos, cirujanos y estudiantes que profesan la facultad de medicina, como de los pintores, dibujantes, architectos y otras personas estudiosas y de curioso ingenio, y así mesmo de gran lustra a esta illustrisima ciudad, por ser el autor hijo de ella, por todo lo quall es raçon se dé a la prensa, procurando adelantar dicha obra, por ser tan larga y costosa, con todo lo pusible, para que llegue al devido cumplimiento de su perfección este es nuestro sentir y assí lo firmamos en Valencia a 23 julio 1686.

El Dr. Juan Joseph Viñau, médico del Hospital general más anciano [rúbrica]; El Dr. Mathias Garcia, catedrático de anatomia [rúbrica]; El Dr. Agustín Abaas, Médico del Hospital general [rúbrica]; El Dr. Felip Juliá Rodríguez, catedrático de prima jubilado [rúbrica]; el Dr. Juan Bautista Gil de Castelldases, catedrático de Prima [rúbrica] 


\section{Documento 4}

Sin localización, 29 de noviembre de 1686

Informe del Consejo Supremo de la Corona de Aragón sobre la pretensión de Crisóstomo Martínez.

A.C.A. Consejo de Aragón. Leg. 0613. nº 12.

[In marg.] Presidente Don Pedro Antonio de Aragón; Don Pedro Villarcampa; Don Juan de Heredia, Marques de Castellón; Don Antonio de Calatayud; Don Juan Baptista Pastor; Don Joseph Rull, Marqués de Canales; Don Pedro Valero; Don Francisco Comes y Jorro, Marqués de Villalba.

\section{Señor,}

Por parte de Crisóstomo Martínez, vecino y natural de la ciudad de Valencia, se dio memorial en el consejo refiriendo que por natural inclinación ha treynta y dos años que vive aplicado a la pintura y juntamente a abrir láminas, que uno y otro se govierna por una misma idea, y que para lograrlo todo, con la valentía y perfección del dibuxo se ha empleado en la inteligencia de las partes, miembros, guesos, arterias, músculos y nerbios que goviernan el movimiento del cuerpo humano de que nazen las verdaderas acciones y posturas, efectuando por este medio la perfección del dibujo y suplicando que, para poder sacar a luz la obra que tiene trabaxada, donde en lámina se declara todo, por ser tan grande el coste que ha de tener en esta obra y haverse de conducir a Reynos estraños donde las prensas, las aguas y las tintas hazen luzir con perfición las estampas, y para cada lámina son menester dos meses cavales de empleo, se digna V.M. mandar que la ciudad y reyno de Valencia le asistan para dicha obra con alguna ayuda de costa proporcionada. Escriviose al virrey que encargase a las personas que le pareciese de la prefessión y médicos que reconociesen esto y que si hallasen ser útil lo avisase remitiendo algunos de los dibujos de estas láminas para verlos aquí, informando de lo que se le ofreciese y pareciese en la materia. A que responde en carta para V.M. de 19 del corriente que haviendo hecho juntar los médicos de primera graduación, huvieron cabal examen de la obra y convinieron era utilísima para médicos y cirujanos, y para el estudio de la nothomía ( $\underline{\text { sic) }}$ porque, aunque ay autores que han escrito sobre esta materia, como en ellos solo concurre lo científico de la facultad y hubieron de valerse de artífices, salieron las obras con muchos yerros en los dibujos, demás que no ay alguna impresión llena como esta, y que, aunque este informe fue tan a favor de la obra, como quien havía de contribuir la ayuda de costa eran la Ciudad y Reyno, quiso oyrles sobre esta pretensión, y la ciudad responde con el informe que remite a que acompaña el que han hecho los médicos. Igual la Diputación respondió que no tenía que añadir, que aguardaría la resolución de V.M. para juntar la casa y deliberar la ayuda de costa. Y que considerando la utilidad de la obra y que le aseguran que el coste ha de pasar de quatro mil libras, debe acompañar la representación de la ciudad y convenir en la ayuda de costa que tiene deliberada con las condiciones que en informe expresa. Y que también será justo ayude algo la Diputación, si bien con cantidad limitada, respecto de sus muchos empeños para que los hijos de aquel reyno se animen al trabajo y se logre el provecho y lustre que de esta obra se ha de seguir y que, jun- 
tamente, remite treynta y quatro dibujos sin contar quatro que ya estaban en esta corte en tabla grande según el orden que ha de guardar en el libro y se presentaran por parte del pretendiente.

El papel que el Virrey remite de los cathedráticos y médicos de aquella ciudad son de sentir ser esta obra muy útil y necesaria para la fácil inteligencia de todas las partes del cuerpo humano, y que redundará en grande utilidad, assí de los médicos, cirujanos y estudiantes que profesan la facultad de medicina, como de los pintores, dibujantes, architectos y otras personas estudiosas y de curioso ingenio.

La Ciudad en su papel refiere también el beneficio y utilidad de la salud pública y assí siente se podrán dar a dicho Chrisóstomo Martínez de la bolsa del Morbo (que es a la que toca cuydar de la salud pública) ochocientas libras en quatro años, docientas en cada uno con obligazion de que dedique esta obra a la ciudad para que conste lo que desea y trabaxa por el augmento y lustre de las ciencias y salud pública y lo que alienta en quanto puede a los que se aplican al estudio de cossas y trabajos grandes como lo es éste. Y también con obligazión de dar fiadores a satisfazión de la ciudad de que dentro de quatro años dará concluyda y impresa con toda perfeción la dicha obra y que, en caso de no hazerlo, haya de restituir las cantidades que hubiere cobrado.

El consejo, haviendo visto con toda atención los informes referidos del virrey, ciudad, cathedraticos y médicos en que expresan el beneficio que de esta impressión de las láminas se ha de seguir al beneficio y utilidad de la salud pública, declarándosse la intelligencia de los guessos, arterias, miembros y músculos del cuerpo humano y reconocido también dichos dibujos que ha remitido, se conforma con disentir. Les dé parezer se haga la obra y que a Chrisóstomo Martínes le dé la Ciudad para ayuda de ella las ochocientas libras que offreze en quatro años de los effectos del morbo, dozientas en cada uno con las conduciones y calidades que expresa. Y también pareze se escriva a los diputados que asistan para dicha obra con alguna cantidad la que les pareziese por ser tan beneficiossa y importante para todo aquel Reyno. [...] Madrid a 29 de Noviembre de 1686.

Documento 5.

Sin localización, 11 de abril de 1687

Solicitud de Crisóstomo Martínez al Rey para que medie con la ciudad de Valencia..

A.C.A. Consejo de Aragón. Leg. 0828. nº 88/1.

\section{Señor,}

Chrisóstomo Martínes, pintor, dice: que en meses pasados fue S.M. servido de aprovar a la siudad de Valencia la aiuda de costa de 800 libras para que pudiesen transportar a Fransia a abrir las láminas deel libro que tiene dibujado y escrito de anothomia ( $\underline{\mathrm{sic}}$ ), respeto de necesitar de aquellas tintas, aguafuerte y aires, para su maior perfección. Con tal, que dicha aiuda costa se la diese en quatro años, cada uno 200 libras, y que antes diesse fiansas de que dentro de dichos quatro años sería completo dicho libro y le dedicaría a la siudad; y aviendo buscado las fiansas para lograr dicha aiuda de costa no las a podido allar en quatro meses (que V.M. se sirvio honrarle con la Real Carta de aprova- 
sión) en que a perdido todo este presioso tiempo y agora se le malogra el de la primavera para asser su viaje. Y respeto, Señor, de que su obra es de tanta considerasión y utilidad para los pintores, escultores, arquitectos, sirujanos y medicos y de tan interesante gloria para la siudad un yjo como el autor como la siudad lo a representado a S.M., viendo a los hombres de maior intelijencia y primeros catredáticos de la Universidad y V.M. lo ha confirmado por sus médicos de camara, y que está oy muy arriesgada en dilatarse por allarse el autor con más de 50 años de edad y algunos achaques que le han ocasionado lo laborioso de ella en más de quatro años de trabajos, y con tan pocos medios, pues en todo este tiempo no a ganado un real en su facultad, antes bien para poder pasar a consumido muchas y ser tan propio de la real clemensia de S.M. el mandar librar no solo esta aiuda de costa, sino otras maiores (en premio de tanta tarea) como V.M. y sus gloriosos antesesores lo an costumbrado y a esta invitasión lo estilan las demás nasiones, no solo con epresivos premios de maravedises, sino con los lustrosos de nobleza y onores a cuia generoça emulasión cresen ingeniosos sujetos en las academias y de mucha utilidad en sus republicas.

Suplica a V.M. sea de su real servisio honrarle con una carta escriviendo a la siudad de Valensia que V.M. se dará por servido de que la primer aiuda de costa de las 200 libras se den agora de contado sin fiansas y que, para las otras que se an de dar, cada año envíe por fiança seis láminas de las 24 que componen el libro y la primera la de la dedicatoria de la siudad, en que la siudad no arriesga más que las primeras 200 libras que parece las merece en satisfación de lo que hasta agora a trabajado sin interés alguno y el desapropio de conducirse a tan remota provincia de bando sin su abrigo ni el de madre $[y]$ quatro ijos, que el maior es de seis años, lo que además que será obra muy de la piedad de V.M., suplicante lo reçibirá y particularmente la poderosa mano de S.M.

\section{Documento 6}

Sin localización, 24 de noviembre de 1691.

Oficio de Cosme Caudel, procurador de Crisóstomo Martínez, a Carlos II.

A.C.A. Consejo de Aragón. Leg. 0929. n 247/1.

\section{Señor,}

El Licenciado Cosme Caudel, presbítero, procurador de Chrisóstomo Martínez, digo que por una Real Carta fue V. M. servido honrar a mi parte permitiendo y mandando a los jurados de la Ciudad de Valencia pudiesen darle y le diesen ochocientas libras de ayuda de costa en quatro años, doscientas libras cada año para abrir y estampar las láminas y ymprimir sus explicaciones deel libro de anothomia (sic) que a compuesto con obligación de dar fianças; y en otra Real Carta despachada en 20 de abril del año 1687 fue V.M. servido aprovar el arbitrio que dichos jurados propucieron a V.M. de dispensar a mi parte la obligación de dar fianças, quando, por no allarlas y ser pobre, quedava frustrada obra tan del bien público como del ynforme que avía precedido constava, en cuya execución, aviendo rezebido mi parte la primer bistrecha de 200 libras, se obligó a dicha ciudad a remitir a la ciudad de Paris (que era el parage elegido para más hermosura y 
claridad de la ympreción, y oy lo es Amberes por averlo desterrado de los reynos de Francia cierta ymbidia), mil y ochocientas estampas cada un año y medio, efetos de seys láminas esto es 300 estampas de cada lámina parte de dicho libro, las quales cirviesen de seguridad para el cumplimiento de la obra y entonces recibiese la segunda bistrecha de 200 libras y así continuar mi parte y la ciudad, asta el cumplimiento de dichas 800 libras. Se ha seguido, Señor, que el libro que avía de constar de veintiquatro láminas se ha augmentado hasta 44 láminas, assi por aver agregado productos de nuevas especulaciones y estudio en que ha descubierto nuevos vaços asta âora no descubiertos, y como por aver mejorado la distribuyción de las partes para mayor y más clara inteligencia, a cuya causa, y por su poca salud, a mi parte más conveniente enplear las fuerças de su caudal y el tiempo en abrir las láminas y no dividirlas en estamparlas como se yvan abriendo, porque, si Dios dispuciese de su vida, era más ymportante dejara más láminas abiertas y la explicación manoescrita que no menos láminas y aquéllas estampadas, pues el estampar y ymprimir es de la ynteligencia de qualquiera y el abrirlas no. Y aviendo acudido a dichos jurados el año 1690 a pedir la segunda bistrecha de 200 libras con demostración de 19 estampas, efetos de 19 diferentes láminas que entonces avía ya abiertas cuyo número excedía en la metad al que en dicho tiempo le competía tener, le fue respondido no dever la Ciudad darle cantidad alguna por aver faltado a lo capitulado de remitir las 1800 estampas cuya respuesta parece al pie del memorial que ago demostración.

Assimesmo ago demostración de 41 estampas efetos de 41 diferentes láminas que, algunos meses han, están abiertas, que verifican que, aunque mi parte a faltado a la formalidad de la obligación, no a cosa alguna de las que conducen al fin para que fundada dicha ayuda de costa, pues, si se concidera para útil deel buen bien público, se ve el libro casi concluso con los aumentos tan considerables como del número de las láminas se ynfiere, si, por la parte de la gloria de la ciudad a quien su hijo dedica la obra, no puede dudarse en su condición a España, pues es el blanco donde aciertan todas las obras grandes para logro de su costa, y a nadie le cita mejor en el presente caso que a mi parte para gozar los frutos de su trabajo, estudio y costas, y por aver coste por si solo dicha obra (excepto las 200 libras de la primer bistrecha) en tiempo tan penoso como aver estado la mayor parte de el enfermo de gota, a apurado su caudal y arbitrio sin que lo aya para papel, estampar, ymprimir, conducir y pagar derechos reales y no alla otro refugio sino el de la piedad de V. M.

Por tanto, a V. M. pido y suplico sea de su real agrado mandar a los jurados de la ciudad de Valencia, que, pues ya no se puede dudar salga a luz el libro de anotomia que a compuesto Chrisóstomo Martínez, para cuyo efeto se le señalaron ochocientas libras de ayuda de coste en quatro años, dar le den las dos que son quatracientas libras para que pueda costear la ympreción, papel, pagar derechos y condución de los libros a Valencia, en cuyo caso le den la última porción de doscientas libras que cumplan el número de las ochocientas. Espera de la poderosa mano de V.M. toda gracia y merced.

[en la cabecera del oficio] En Madrid a 24 de Noviembre de 1691; Desde el despacho como suplica; y adviértase a la parte que ha de dar a cada un ministro un libro destos y dos al presidente y tesorero general. Las láminas se las llevo el P. Borja. 


\section{Documento 7}

Sin localización, 1693.

El licenciado Cosme Caudal reclama la cantidad pactada por el libro de Anatomía. A.C.A. Consejo de Aragón. Leg. 0932. nº 87/1.

El Licenciado Cosme Caudel, presbítero, procurador de Chrisóstomo Martínez, dice que, en bista de quarenta y una estampas efetos de quarenta y una diferentes láminas de que consta el libro de anatomía que ha compuesto mi parte, fue V.M. servido en 8 de diciembre más cerca passado, mandar a los jurados de la ciudad de Vallencia diessen a Chrisóstomo Martínez quatrocientas libras, parte de aquellas ochocientas de que se havia hecho gracia en ayuda de costa para inprimir este libro. Dispensando V.M. la obligación a que estaba tenido de remitir cada un año y medio mil y ochocientas estampas productos de seis diferentes láminas que sirviesen de siguridad para el cumplemento de la hobra, $\mathrm{y}$, habiéndose acudido a los jurados por las 400 libras, responden no deber dar cantidad alguna por no haver remitido todas las 1800 estampas que se habría obligado dentro del término y, si bien este desconsuelo ha mortificado el ánimo de Chrisótomo, su firmeza y amor a la patria le ha alentado a que, aplicando sus fuerças personales y confiando en la paternal providencia de V.M. ha compuesto siguiendo parte de dicho libro, en una de la lámina que consta de vara y tres quartas de alto, y contiene un retrato cierto y fidedigno desde la nervologia(?) de el hombre de el tamaño del natural, con tal aptitud que a un tiempo se logra la vista general de quanto contiene el original con la qual se evitaran los varios (ilegible) que sobre la composissión de la nervologia(?) a visto en diferentes autores (como si esta materia fuera oppinable), yerro a que los conduce a no reducir a especular una práctica las noticias de las antiguas teóricas.

Y reconociendo será lástima que obra que estará perfeta y la gracia de V.M. concedida, queda en este estado por falta de medios, privando al público de las conveniencias que le han de resultar, suplico a V.M. sea de su real grado repetir su Real Orden mandando a los jurados de Vallencia que toda suplica cessante [...]

\section{Documento 8.}

Sin localización, noviembre de 1695.

Respuesta de Carlos Homo dei Moura y Pacheco, virrey de Valencia, sobre el estado de la obra de Martínez.A.C.A. Consejo de Aragón. Leg. 0848. 52/3.

Señor mío, en carta del 16 del corriente me dize V.M: de orden del Consejo que, siendo virrey de este reyno el señor Conde de Zifuentes dio S.M. permiso a Chrisóstomo Martinez para que se abriese unas láminas de los huesos humanos $\mathrm{y}$, deseando el consejo saber el estado de esta materia, havía acordado que V.M. me participase esto para que, informándome, avise lo que huviese sin que se suspendan las diligencias que se juzguen convenientes para la pública utilidad. $\mathrm{Y}$ en respuesta de esta orden, diré a V.M. que, haviendo solicitado noticias he adquirido que con Chrisóstomo Martínez ajustó esta ciudad le daría ochocientas libras por toda la obra que para pasar a Paris y empecar las láminas. Se le dieron doscientas. Sepa, dice el síndico de la ciudad, costa de esta cantidad, y 
no más, que este hombre fue a Paris, que empezó esta hobra y ha embiado unas diez y nueve estampas de diferentes huesos y figuras. Que, estando continuando, se rompió la paz y empeçando la guerra le desterró el rey de Francia. Que no sabe dónde está este hombre ni a buelto a escribir a la ciudad, ni a embiado ninguna lámina, ni en la ciudad ay más de las 19 estampas sin que por ahora se ofrezca otra cosa que avisar a V.M. que se servirá de participarlo al consejo.

\section{AGRADECIMIENTOS}

Queremos expresar nuestro agradecimiento a Antonio Carreras Panchón y a Noelia Caro Martínez, que colaboraron con interesantes aportaciones en la preparación final del manuscrito.

Recibido: 1 de septiembre de 2010

Aceptado: 13 de mayo de 2011 